\title{
Assessment of Passenger Security in Paratransit Buses
}

\author{
Andrzej Morka, Military University of Technology, Poland \\ Lesław Kwaśniewski, Warsaw University of Technology, Poland \\ Jerry W. Wekezer, Florida A\&M University- \\ Florida State University, College of Engineering
}

\begin{abstract}
The main objective of this study was to assess usefulness of 3-D, nonlinear dynamic, explicit computer codes for transit safety and security research. An analysis of response of a paratransit bus structure under loading caused by high explosive (HE) detonation is presented. It was assumed that the cubic HE charge detonates in the air near the bus. The ground was modeled as a rigid stationary wall. The problem was studied using LS DYNA, an explicit, 3-D, dynamic, nonlinear finite element program. The HE detonation and the processes of shock propagation in the air were modeled using the mesh with the Euler's formulation. The Euler's mesh was modeled as a rectangular prism sufficiently large enough to cover the entire bus structure. The nonreflecting boundary conditions on the top and side surfaces of the Euler's domain and the sliding interface on the bottom side for the contact with the ground were assumed.

A finite element model of the Ford Eldorado Aerotech 240 paratransit bus was developed for this study. This model consisted of 73,600 finite elements and had 174 defined properties (groups of elements with the same features) and 23 material models.
\end{abstract}


Computational analysis provided useful information about dynamic deformations and damage inflicted to the bus structure under load blast wave activated by the $H E$ detonation. It allowed for detailed, rigorous analyses of time histories of accelerations, velocities, deformations, and stresses. Resulting acceleration and overpressure histories were correlated with expected blast injuries of the bus passengers. The data obtained can be used to improve passenger safety and to reduce the threat of suicidal terrorist attacks against public transit. Changes in the bus structure and replacement of some materials to build a safer class of vehicles can be carefully considered and implemented.

\section{Introduction}

Two different approaches can be used for analysis of the structural response of a bus under loading caused by high explosive (HE) detonation. The first method is based on applying a previously known function of loading (pressure surfaces) to the structure. The time space characteristics of pressure loads can be defined based on data collected in a series of experiments. The same methodology is used for building the mine impulse-loading model (Westine et al. 1985). Although simple, this method of analysis of the structure behavior under blast loading leads to serious limitations. First, no interaction between the structure response and the acting force (blast wave) is included. Yet the actual response of the structure may have a significant effect on magnitude and distribution of air pressure in time, which resulted in this response. Moreover, extrapolation from a finite set of data to specific conditions (geometry, type of HE, its location, etc.) introduces additional modeling errors. Simultaneous modeling and interaction of both processes-the response of the structure and the explosion with shock generation and its propagation in the air-is free of these disadvantages. Insufficient computational power of commonly accessible computers did not allow for implementing this concept in the past. Rapid growth of CPU speed in the new generation of mainframe computers allows for solving these problems. For example, Vulitsky and Karni (2002) successfully analyzed a ship structure subjected to HE detonation. The authors simplified their model to a plate loaded by a pressure wave. Another work presented the results of calculations for a response of protective structures to an internal explosion with blast venting (Kivity 1993), where a rectangular prism shell with venting holes was used as a structural model. A concrete structure with ambient inside and outside air was modeled. One-fourth of the entire physical problem was considered due to symmetry. More examples can be found in the literature, 
which provide evidence that this approach is becoming dominant. This study continues these trends, which combines advanced modeling of bus structure with simultaneous modeling of blast pressure waves.

\section{Explosion Model}

A preliminary analysis of the structural response of a bus under loading caused by $\mathrm{HE}$ detonation was performed. Collected data regarding the amount of explosive materials and their possible location during suicidal terrorist attacks on a bus led to several physical assumptions. An explosive charge of $13 \mathrm{~kg}$ of $\mathrm{C} 4$ detonated in the air, 1 meter above the ground and at a distance of 1.5 meters from the bus (see Figure 1), was assumed. The HE was considered as a cube with a $20 \mathrm{~cm}$ edge

\section{Figure 1. Geometry of a Bus Structure under Loading Caused by Explosion of an HE in the Air Domain}

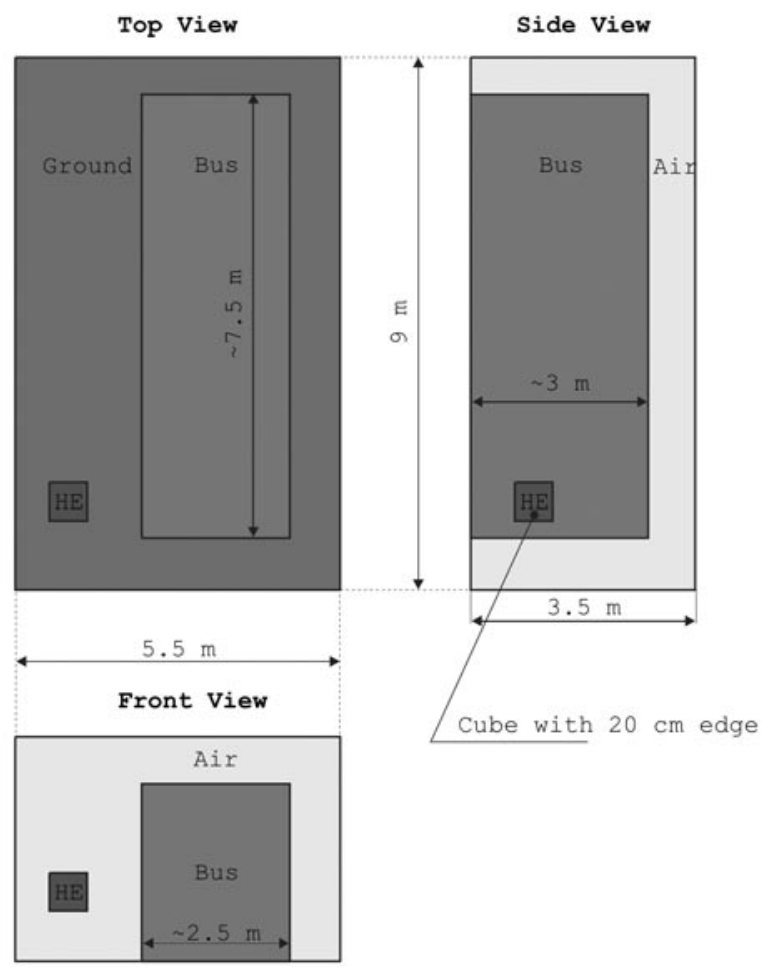


and the point of initiation of detonation in its center. The ground was modeled as a rigid stationary wall. The problem was studied using LS DYNA, an explicit, 3$D$, nonlinear finite element code. The HE detonation and the processes of shock propagation in the air were modeled using the mesh with the Euler's formulation. This option was applied using the Arbitrary Lagrangian Eulerian Algorithm (ALE), available in LS-DYNA. The Euler's grid, modeled as a rectangular prism ( $\mathrm{WxLxH}$ : $5.5 \times 9 \times 3.5 \mathrm{~m}$ ), was sufficiently large enough to cover the entire bus structure. The nonreflecting boundary conditions on the top and side surfaces of the Euler's domain and the sliding interface on the bottom side for the contact with the ground were assumed. Figures 2 and 3 show the finite element model (FEM) developed for explosion and shock propagation modeling in the air domain.

\section{Figure 2. Isometric View of the FEM with Euler's Domain}

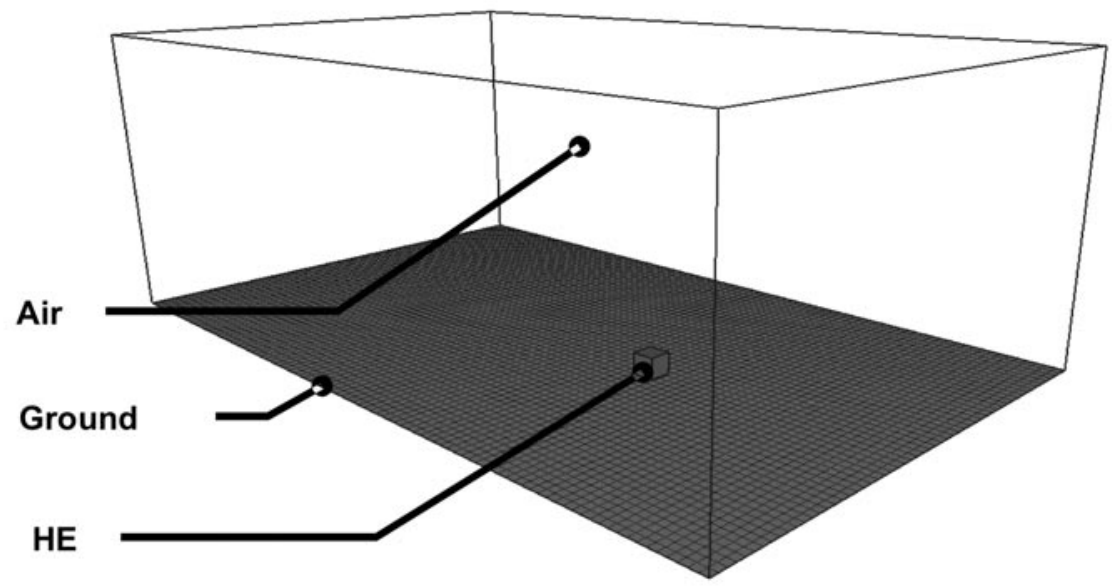

The bottom side of the cube in Figure 2 represents ground modeled as a rigid wall. The FE ground model consists of 5,096 shell elements with a typical edge length of $10 \mathrm{~cm}$. Figure 3 presents the cross section of the Euler mesh along with HE charge symmetry plane normal to the bus. The Euler formulation allows for material mixing and mass transfer between FEM elements. The zoomed-in rectangle in Figure 3 shows different grid regions. The entire mesh consists of 241,104 hex elements with a typical edge length of $1 \mathrm{~cm}$ for $\mathrm{HE}$ to a maximum of $10 \mathrm{~cm}$ for air and a suitable intermediate zone between them. 


\section{Figure 3. FEM for Euler's Domain: HE and the Air}

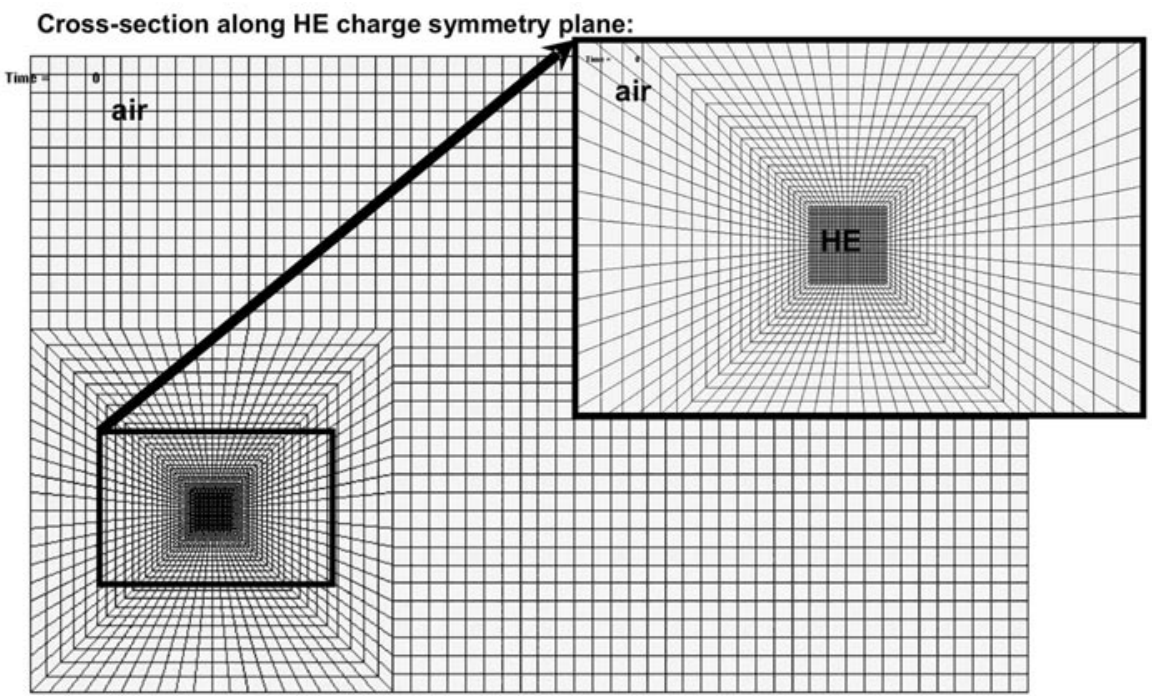

Cross section along HE charge symmetry plane normal to the bus. The area close to the HE location is zoomed in the rectangle in the upper-right part of the figure.

The detonation process was implemented through the automated programmed burn model, supported by LS-DYNA. Velocity of the Detonation Wave (DW) and the thermodynamical parameters on DW front were assumed to be known in this model. A sphere surface was assumed as the best DW front shape since the initiation of detonation begins in the center point of HE charge. The energy contained in the HE was assumed as immediately released inside the front of detonation wave as a result of the chemical reaction

$$
H E \rightarrow P D+Q
$$

where:

$Q$ represents the heat effect of this reaction

$P D$ are products of detonations 
In addition, 100 percent of HE mass was assumed to transfer to PD. The Jones Wilkins Lee (JWL) Equation (1) was used to characterize the products of detonation of the $\mathrm{C} 4 \mathrm{HE}$ :

$$
p=A\left(1-\frac{\omega}{R_{1} \bar{\rho}}\right) \exp \left(-R_{1} \bar{\rho}\right)+B\left(1-\frac{\omega}{R_{2} \bar{\rho}}\right) \exp \left(-R_{2} \bar{\rho}\right)+\frac{\omega \bar{e}}{\bar{\rho}}
$$

where:

$$
\begin{array}{ll}
\rho & \text { equals } \frac{\rho_{H E}}{\rho} \\
e & \text { represents } \rho_{H E} e \\
\rho_{H E} & \text { refers to density of the HE } \\
p & \text { represents pressure of PD } \\
e & \text { is specific internal energy of PD } \\
\rho & \text { equals density of PD }
\end{array}
$$

$A, B, R_{1}, R_{2}, \omega$ are empirical constants determined for the specific type of $\mathrm{HE}$

Table 1 includes values of all these constants found in the JWL equation (Wlodarczyk 1994) for C4 HE used in this work.

Table 1. Constants for the JWL Equation of State for PD of C4

\begin{tabular}{|c|c|c|c|c|c|c|}
\hline Type of HE & $\begin{array}{c}\rho_{H E} \\
{\left[\mathrm{~kg} / \mathrm{m}^{3}\right]}\end{array}$ & $\begin{array}{c}A \\
{[\mathrm{GPa}]}\end{array}$ & $\begin{array}{c}B \\
{[\mathrm{GPa}]}\end{array}$ & $\begin{array}{c}R_{1} \\
{[1]}\end{array}$ & $\begin{array}{c}R_{2} \\
{[1]}\end{array}$ & $\begin{array}{c}\omega \\
{[1]}\end{array}$ \\
\hline $\mathrm{C} 4$ & 1,601 & 609.77 & 12.95 & 4.5 & 1.4 & 0.25 \\
\hline
\end{tabular}


The equation of state for an ideal gas with the specific heat ratio of $7 / 5$ was applied for the air. Coupling between Euler (air domain) and Lagrange (bus structure) formulations was accomplished by using an appropriate LS DYNA feature called CONSTRAINED_LAGRANGE_IN_SOLID. The interaction between bus structures and-shock was modeled by Penalty Algorithm, an LS-DYNA feature, while shock and ground interaction was modeled as a sliding interface.

\section{Bus Model}

Since blueprints and design data of the paratransit bus were not available, the reverse engineering process (Chenga et al. 2001) was adopted to acquire geometric data and to develop the FEM for computational mechanics analysis. The actual bus was carefully disassembled into individual parts to allow for accurate geometric data acquisition. All structural components were taped, scanned, digitized, and mapped into the computer. In addition to geometric entities (e.g., surfaces, curves, points), material and structural properties (e.g., thickness, material type, and weight) were also collected. Subsequently, the scanned geometry for each part was imported into a preprocessor. After all nonstructural components were removed from the bus, its structure was thoroughly examined. The disassembly process resulted in full exposure of the connections of the major components. Joints among the structural parts, such as hinges, rivets, welds, bolts, and rubber pads were identified and were appropriately modeled on the computer using multipoint constraints (MPCs), spot welds, node merging, and node tying.

Scanned geometric data were imported into MSC/PATRAN (2001), a graphical preprocessor, in which FE meshes were constructed and modified. Decisions regarding element formulations, material models, material characteristics, contact algorithms, MPCs and connections, loading and boundary conditions, solution parameters, and others were made to complete the model (Bathe 1998; Omar et al. 1999). Limited laboratory tests were performed for selected structural components and material samples to identify material parameters and connection characteristics.

MPC provided an opportunity to model connection bolts, screws, and welds with failure (LS-DYNA 1999). An example of modeling of spot weld in the bus cage using MPCs can be found in (Kwasniewski et al. 2002).

Self-automatic contact was applied to all the elements in the model. Twenty-three material types were identified for the structural components of the actual bus. The 
bus body was modeled using two layers of composite material with an additional honeycomb layer placed in between them. Composite layers were modeled using shell elements while honeycomb was represented by solid elements.

Significant numbers of the vehicle components were modeled with shell elements since most of the structural parts of the bus were made of metal and composite sheets. A fully integrated quad element number 16, available in LS-DYNA, was selected for analysis as the most reliable element formulation, based on several numerical tests (Alem 1996). The actual Eldorado paratransit bus is shown in Figure 4, while its final FEM is shown in Figure 5.

Figure 4.

Ford Eldorado Paratransit Bus
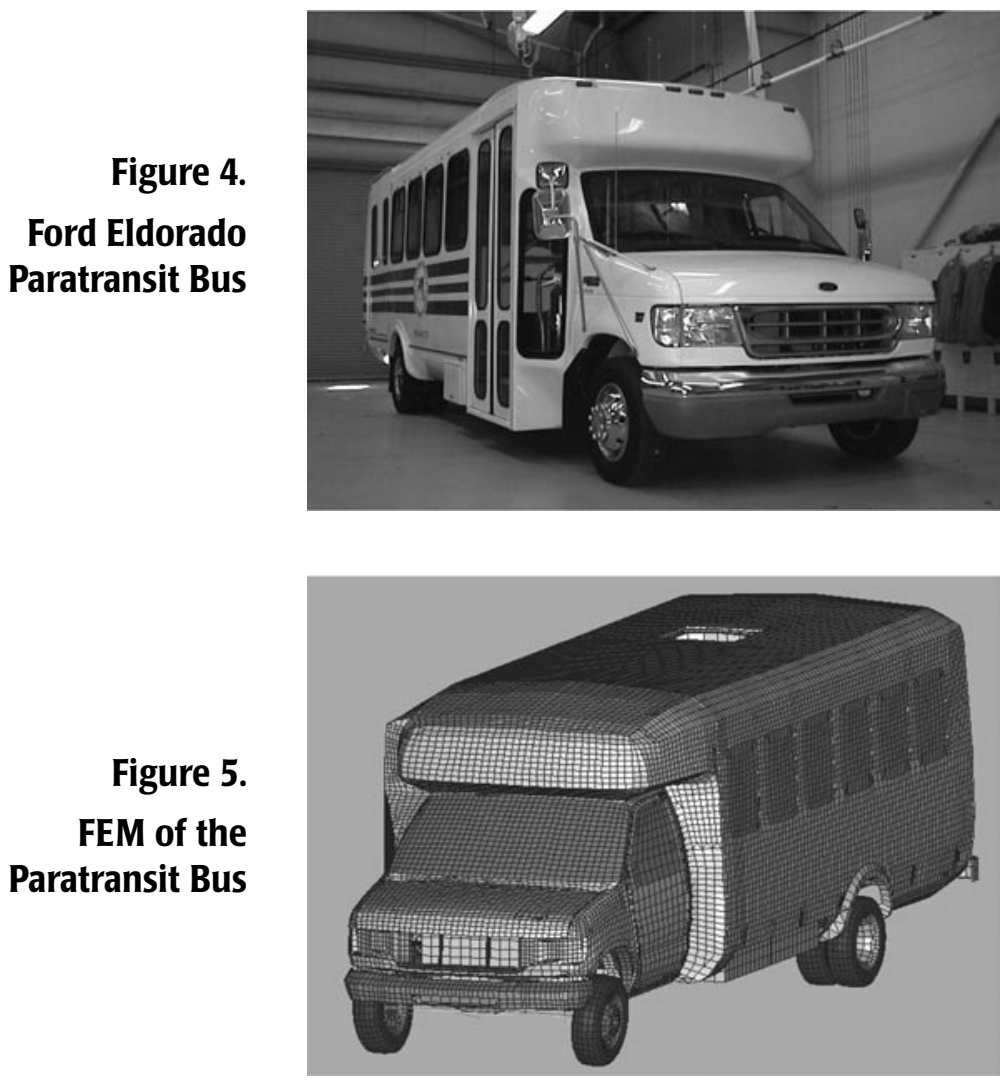

The bus FEM consisted of 174 parts, 23 material models, and 73,595 elements. A summary of the final FEM of the bus is provided in Table 2. 
Table 2. Summary of the FEM Bus

\begin{tabular}{|l|l|r|}
\hline 1 & Number of parts (LS-DYNA)/ Property sets & 174 \\
2 & Number of material models & 23 \\
4 & Number of nodes & 67,788 \\
5 & Number of solid elements & 9,612 \\
6 & Number of shell elements & 63,271 \\
7 & Number of beam elements & 712 \\
\hline
\end{tabular}

\section{Analysis and Results}

Selected results of this study are presented below. A cube near the front door of the bus in Figure 6 represents the initial position of the HE charge.

\section{Figure 6. Initial Position of HE Charge and Bus Structure}

$$
\text { Time - } 0
$$

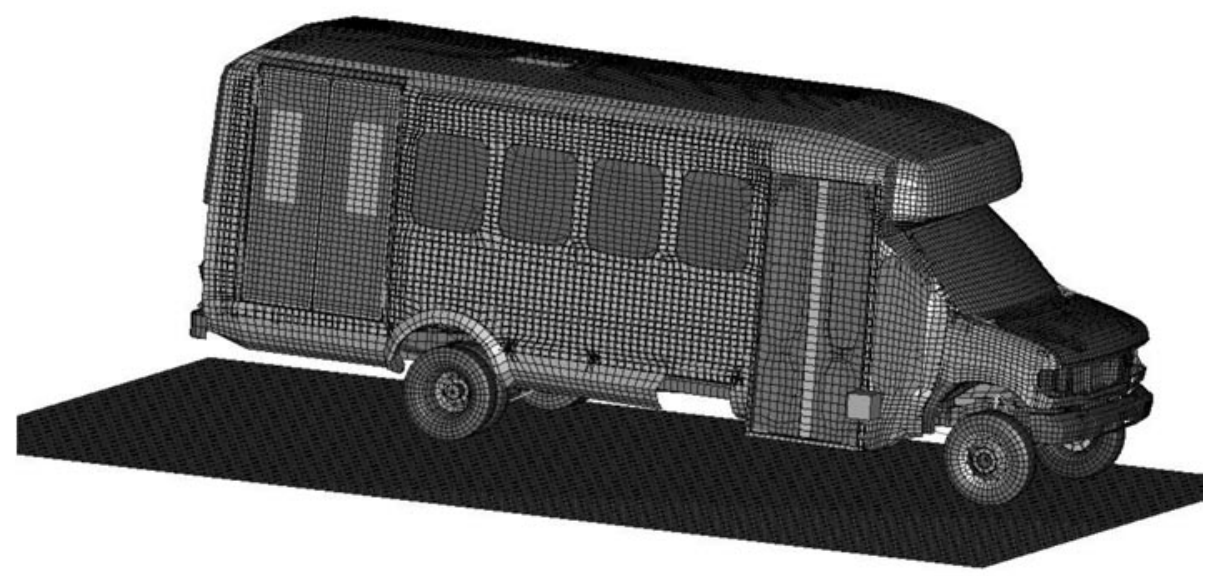

The bus structure was immersed in the Euler air mesh domain so that the distance from an arbitrary element to the nearest boundary was at least $0.5 \mathrm{~m}$. Figure 7 shows the isosurfaces of the pressure in the air after 270 microseconds from the initiation of detonation. The pressure fringes were cut off between $0.101 \mathrm{MPa}$ and $0.5 \mathrm{MPa}$ for better visualization. The interior surface surrounds space where the 
blast pressure is larger then $0.5 \mathrm{MPa}$, while the exterior surface is the boundary of the outside region with the pressure smaller then $0.101 \mathrm{MPa}$. A blast wave activated by the HE detonation is shown in Figure 7 .

\section{Figure 7. Isosurfaces of the Pressure in the Air after $\mathbf{2 7 0}$ Microseconds from Initiation HE Detonation: A Blast Wave Activated by the HE Detonation.}

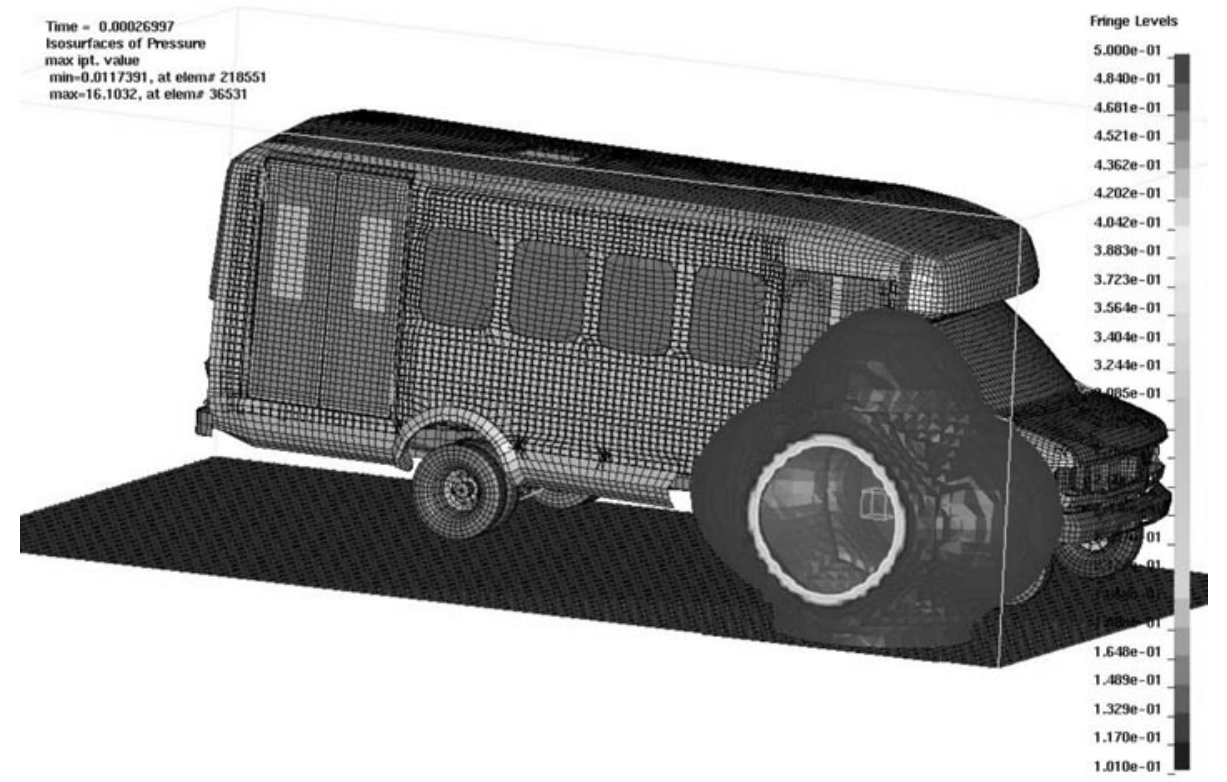

Figure 8 depicts the deformation and damage to the bus structure after the first 30 milliseconds. Interestingly, although HE charge has been detonated outside the bus, the bus structure behaves at some point of time as a pressurized balloon with vent holes. The shock effect and accelerations were examined for four selected points located on the plane of the longitudinal cross section through the bus (Figure 9). 
Figure 8. Damage after First 30 Milliseconds

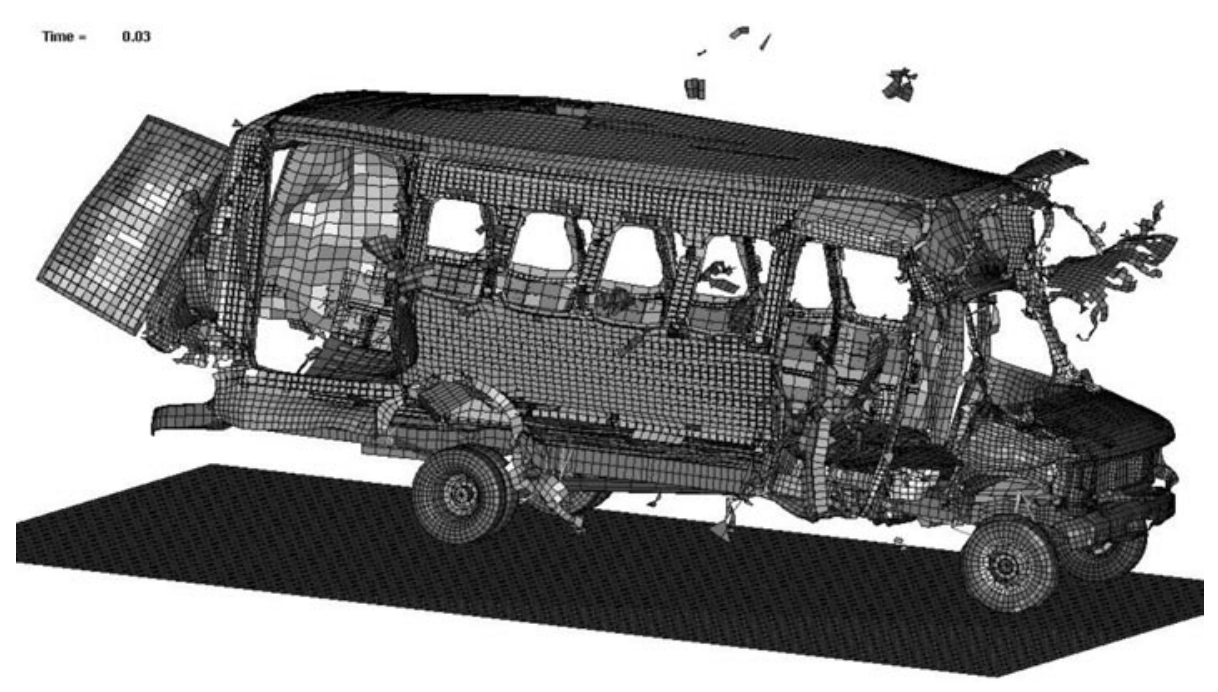

Figure 9. Longitudinal Cross-Section of the Bus Structure

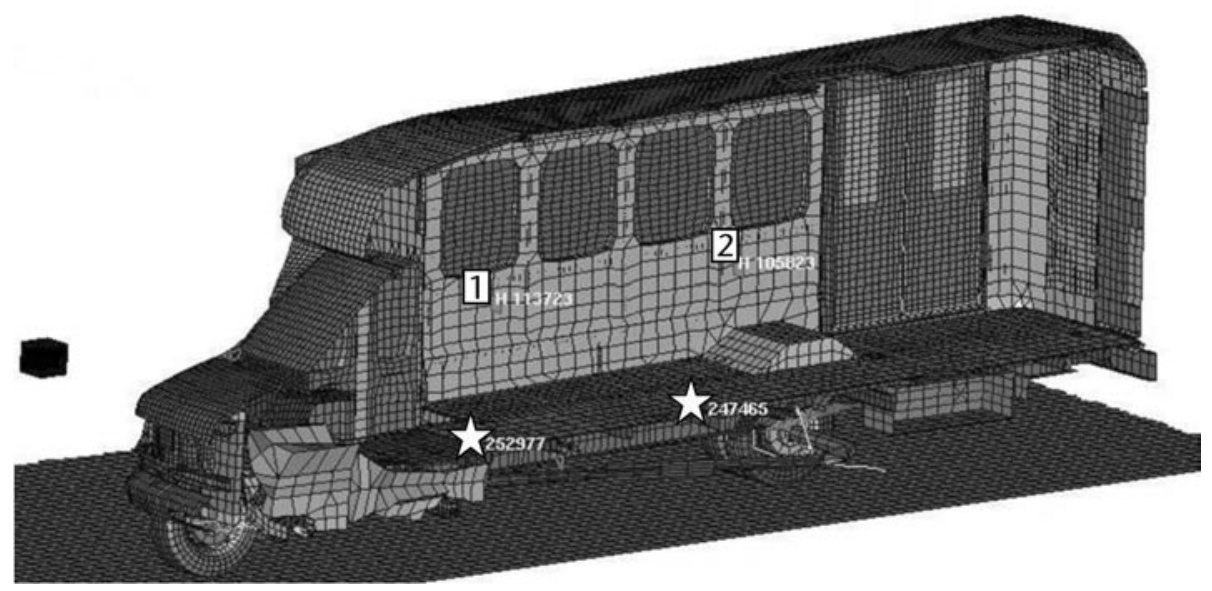


Asterisks were used to mark two points for acceleration analysis; two squares indicate pressure histories. Figure 10 presents the velocity time history for selected points of the bus structure.

\section{Figure 10. Velocity Time History for Selected Points}

(see two asterisks in Figure 9)

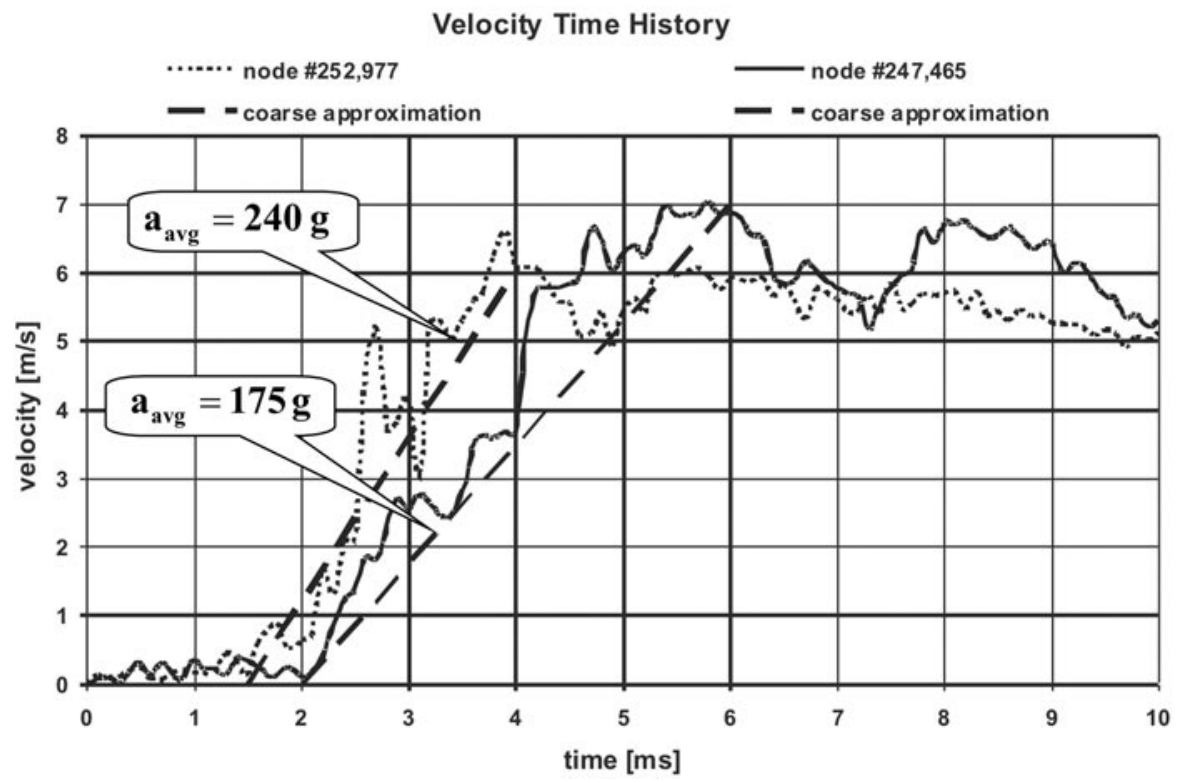

Average accelerations calculated from coarse approximations of velocity versus time curves reach values of $175 \mathrm{~g}$ and $240 \mathrm{~g}$, where $\mathrm{g}$ represents the earth acceleration. Such accelerations result in brain damage or a leg fracture as shown in Table 3. Table 3 shows injury criteria resulting from a mine blast. These criteria were developed by Alem (1996), and were successfully applied by Williams and FillionGourdeau (2002).

Another dangerous factor affecting human life is a short duration of over/under pressure changes, referred to as shock effect. Tables $4 \mathrm{a}$ and $4 \mathrm{~b}$ show the summary of the experimental studies of damage effects caused by high-energy explosives (Turin, unpublished materials). Although rabbits, rats, and pigs were used in these studies, similar effects can be expected for humans. Results from the pig tests are 
Table 3. Mine Blast Acceleration Injury Assessment

\begin{tabular}{|l|l|l|}
\hline Part & Shock/Acceleration & Injury \\
\hline Head & $\mathrm{a}=150 \mathrm{~g}$ for $2 \mathrm{~ms}$ & High risk of brain damage \\
Pelvis & $\mathrm{a}=40 \mathrm{~g}$ for $7 \mathrm{~ms}$ & High risk of spinal cord damage \\
Feet & $\mathrm{v}=3.5$ to $5.0 \mathrm{~m} / \mathrm{s}$ & Apparition of lower leg fracture \\
\hline
\end{tabular}

Source: Alem 1996.

Table 4a. Overpressure and Blast Injuries

\begin{tabular}{|l|cc|}
\hline \multirow{2}{*}{\multicolumn{1}{|c|}{ Injury }} & \multicolumn{2}{|c|}{$\begin{array}{c}\text { Overpressure Values* } \\
{[\mathrm{kPa}]}\end{array}$} \\
\cline { 2 - 3 } & Rabbits & Pigs \\
\hline Barotrauma & 56 & 56 \\
Mild contusion & 134 & 130 \\
Moderate injury & 217 & 237 \\
Heavy injury & 280 & 371 \\
Lethal injury & 490 & 1074 \\
\hline
\end{tabular}

*Turin, unpublished materials.

\section{Table $4 \mathrm{~b}$. Cutoff $\Delta \mathrm{P}$ Values and Blast Injuries}

\begin{tabular}{|l|cc|}
\hline \multirow{2}{*}{\multicolumn{1}{|c|}{ Injury }} & \multicolumn{2}{|c|}{ Cutoff $\triangle P$ Values* } \\
& {$[\mathrm{kPa}]$} & \\
\cline { 2 - 3 } & Rabbits & Pigs \\
\hline Barotrauma & 33 & 113 \\
Lung hemorrhage & 43 & 102 \\
Lethal (death) & 180 & 880 \\
\hline
\end{tabular}

*Turin, unpublished materials. 
of particular interest because of the pigs' similarity to human mass and structure of body tissues. The cutoff pressure $\Delta P$ is also dangerous for humans since it can cause damage, as shown in Tables $4 a$ and $b$.

Figure 11 presents the pressure time history for selected points of the bus structure marked as two squares in Figure 9.

\section{Figure 11. Pressure Time History for Selected Points}

(see two squares in Figure 9)

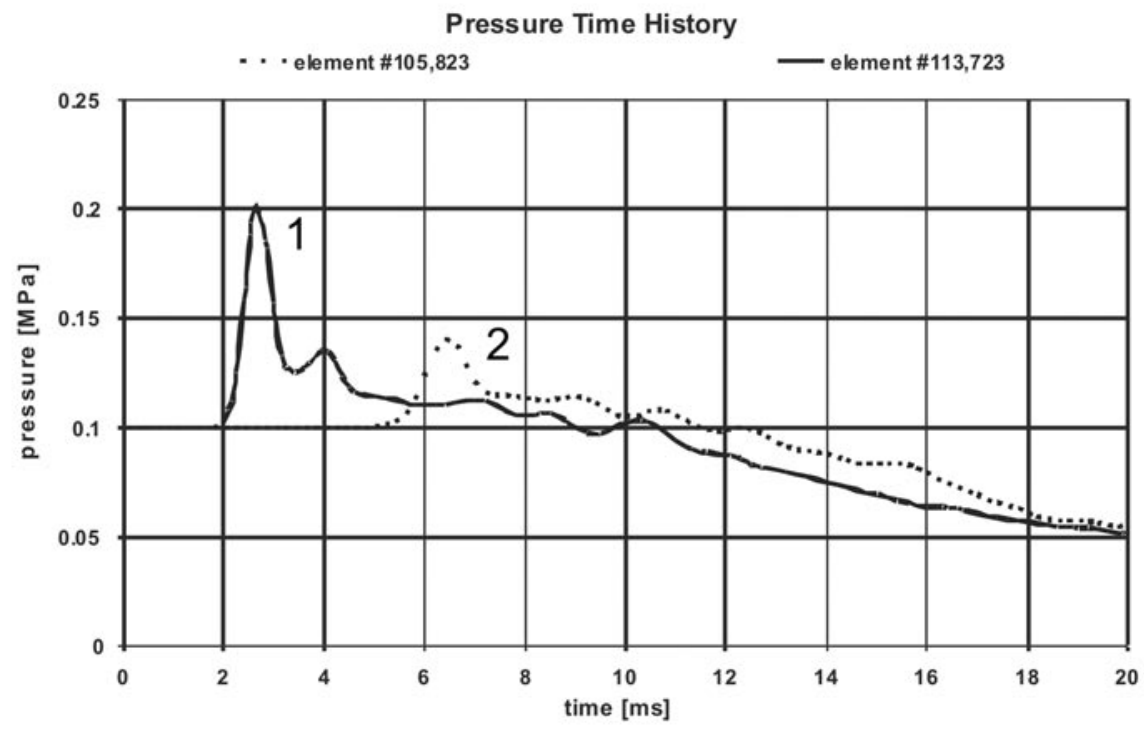

The overpressure reached a value of about $100 \mathrm{kPa}$ at the first point and $40 \mathrm{kPa}$ at the second one, while the cutoff $\Delta \mathrm{P}$ pressures were $150 \mathrm{kPa}$ and $90 \mathrm{kPa}$, respectively. Passengers located near these places were likely to be subjected to barotrauma, mild contusion, and lung hemorrhage.

\section{Conclusions}

The principal objective of this project was to carry out the feasibility study of capabilities of FEA for assessment of structural response of a paratransit bus, and survivability of passengers under a suicide terrorist attack. An appropriate meth- 
odology was developed and was successfully used for this problem. Formulation of further, more practical conclusions, would require additional studies. Future research should include a validation process of the bus FEM, numerical data of the shock propagation in the air, as well as validation of shock/structure interaction models through experimental data.

\section{Acknowledgements}

Partial funding for this project was provided by the Transit Office of the Florida Department of Transportation (FDOT). The FEM of the paratransit bus was sponsored by FDOT. The authors wish to acknowledge the assistance and support from Robert Westbrook, project manager, and Paul Johnson, Jr. The tear down of the bus was professionally performed by QMG Consulting Inc. Thanks are due to Paul Queen and Cecil Carter from QMG Inc. for their excellent work and technical support. Our gratitude also goes to research assistants Hongyi Li and Ravi Nimbalkar for their participation in the digitizing and model development of the paratransit bus. 


\section{References}

Alem N. M. 1996. Mine blast acceleration injury assessment: Methods, criteria and software. Report \# 97-04, USAARL.

Bathe, K-J. 1998. What can go wrong with FEA? Mechanical Engineering. http:// www.asme.org/pdf/.

Chenga, Z. Q., J. G. Thackera, W. D. Pilkeya, W. T. Hollowell, S. W. Reagana, and E. M. Sieveka. 2001. Experiences in reverse-engineering of a finite element automobile crash model. Finite Element Anal. 37: 843-860.

Kivity Y. 1993. Response of protective structures to internal explosion with blast venting. MSC World Users Conference, Arlington, VA.

Kwasniewski L., J. W. Wekezer, and H. Li. 2002. Development of finite element model for Ford Eldorado transit bus. Theoretical Foundations of Civil Engineering. 10th Polish-Ukrainian Transactions, Warszawa.

LS-DYNA Keyword User's Manual (Nonlinear Analysis of Structures). 1999. Livermore Software Technology Corporation: Livermore, CA.

LS-DYNA Theoretical Manual. 1998. Livermore Software Technology Corporation: Livermore, CA.

MSC/PATRAN Reference Manual. 2001. MSC Software Corporation: Santa Ana, CA.

Omar, T. A., C. D. Kan, N. M. Bedewi, and A. Eskandarian. 1999. Major parameters affecting nonlinear finite element simulations of vehicle crashes. Crashworthiness, Occupant Protection and Biomechanics in Transportation Systems. The ASME International Mechanical Engineering Congress and Exposition, Nashville, TN.

Turin M. V. Investigation of fragmentation and damage effects caused by highenergy explosives. Special Materials, Ltd. www.npo-sm.ru/blast/art3.pdf.

Vulitsky M. Z., and Z. H. Karni. 2002. Ship structures subjected to high explosive detonation. 7th International LS-DYNA Users Conference, Dearborn, MI.

Westine, P. S., B. L. Morris, P. A. Cox, and E. Z. Polch. 1985. Development of computer program for floor plate response from land mine explosion. Technical Report No. 13045, US Army Tank-Automotive Command, Warren, MI. 
Williams K., and Fillion-Gourdeau F. 2002. Numerical simulation of light armored vehicle occupant vulnerability to anti-vehicle mine blast. 7th International LS-DYNA Users Conference, Dearborn, MI.

Wlodarczyk E. 1994. Wstep do mechaniki wybuchu, PWN, Warsaw.

\section{About the Authors}

ANDRZEJ MORKA (andrzej.morka@neostrada.pl) is a doctoral candidate at the Military University of Technology, Warsaw, Poland. He worked on a research project related to armor penetration and was sponsored by $A R L$ as a research assistant in the Crashworthiness and Impact Analysis Laboratory at Florida A\&M University-Florida State University (FAMU-FSU) College of Engineering from January - December 2003.

LESLAW KWASNIEWSKI (I.kwasniewski@il.pw.edu.pl) is an assistant professor at the Institute of Structural Mechanics, Department of Civil and Environmental Engineering, Warsaw University of Technology in Poland. He also worked as a post-doctoral research associate in the Crashworthiness and Impact Analysis Laboratory at FAMU-FSU College of Engineering on several projects between 2002 and 2005.

JERRY W. WEKEZER (wekezer@eng.fsu.edu) is a distinguished professor at FAMUFSU College of Engineering in the Department of Civil and Environmental Engineering. He is also a director of the Crashworthiness and Impact Analysis Laboratory where the study presented in this article was carried out. 